Industrial Professor in the Departments of Mechanical Engineering and Metallurgy at the Imperial College of Science and Technology. This is the most obvious part of what will be an important scheme for collaboration in teaching and research between the Imperial College of Science and Technology and the British Welding Research Association.

The resources of the research association and the college are to be combined to expand the teaching of welding technology at all levels. Undergraduates at the college will be able to spend short periods of instruction at the association's laboratories, and the association's staff will help the college to provide courses of lectures for postgraduate students. A number of short refresher courses, of three to four weeks in specific fields of the technology, will be held for staff from industry by the college and association jointly. These will be held partly at the college and partly at the association's conference centre at Abington, near Cambridge. The scheme also envisages close collaboration in research; already work of interest to the association is being carried out at Imperial College. The facilities of the two departments of the college will be available to the association staff and the specialist equipment of the association will be available to the college. Younger staff members in the association will also be able to qualify for higher degrees from the college.

\section{Watching the Sun}

A DISH aerial one mile in diameter which can adjust to the position of the Sun at one second intervals is clearly not a practical proposition, but a new radio heliograph two miles in diameter which was opened on September 22 at Calgoora, Australia, is designed to observe the Sun with equivalent resolution. Complete pictures of the solar disk showing great detail will be taken at one second intervals by the telescope, so that close observation of the rapid changes that occur during solar flares and sunspot activity will be possible. With an operating frequency of 80 megacycles, the resolution is thought to be about 2 minutes of arc. The telescope consists of 96 acrials set up in fixed positions round a circle two miles in diameter. Each aerial is a dish $45 \mathrm{ft}$. in diameter and is automatically driven to follow the Sun for 4 hours a day while the pictures are taken.

Signals from each aerial are amplified 100 times before being transferred by cable to the central point. The synthesis technique is the basis of the complicated calculations which are then made by computers, correlating the output of all possible pairs of aerials. The heliograph is part of the Australian Commonwealth Scientific and Industrial Research Organization's Solar Observatory, and was designed by Dr Paul Wild. It has taken five years to build and has been financed by donations of $£ 230,000$ from the Ford Foundation.

Within the circle of the radio heliograph at Calgoora the Physies Division of the CSIRO has set up a $12 \mathrm{in.}$ optical telescope. It incorporates a specially developed filter which cuts down scanning time to only a few seconds, and should pick out details of areas only 250 miles in diameter on the Sun's surface 93 million miles away. The cine-magnetograph is under the direction of Dr R. G. Giovanelli, chief of the division, and is supported by the United States National
Aeronautics and Space Administration. A small telescope, which watches for solar flares as part of the world-wide patrol network, completes this array of tools for the Sun specialist.

\section{Water Games}

The Hydraulies Research Station of the Ministry of Technology at Wallingford (Berkshire) still finds that most problems in open channel flow must be solved by building models and running water through them. One result is that the station's programme of investigations at any time has a pleasing diversity. At present, for example, the station is studying the effects of very long waves in a model of the proposed Brighton yacht marina. The model is built beneath a twodimensional array of lights, and the reflexions in the water with an exposure time equal to one wave period are photographed. This provides information about the maximum slope of the water surface. Opponents of the marina at Brighton will be distressed to hear that so far the work at Wallingford has shown no technical objections to the design.

The station is also intending to build a large model of Morecambe Bay to test the feasibility of a barrage and to determine the best position for one. The chief concern will be to determine the effect of the barrage on siltation and erosion in Morecambe Bay, particularly at the ports of Heysham, Fleetwood and Barrow in Furness. The investigation is part of a larger study being carried out by Sir Alexander Gibb and Partners for the Water Resources Board.

Civil disturbances at Hong Kong have not prevented the station setting out to study the building of a tunnel across the harbour by sinking prefabricated concrete sections, each $424 \mathrm{ft}$. long and weighing 30,000 tons. The sections would be floated into place and then sunk, a delicate operation with such enormous sections. If the hydrodynamic forces acting on the tunnel sections are not precisely $\mathrm{kn} \approx \mathrm{wn}$, there is a danger that the tunnel will either sink too fast or bob up again to the surface. The necessary information is being supplied by the use of a 'Perspex' model at Wallingford, built to a scale of 1 in 100 . There is also a feasibility study of the disposal of London sewage by pipeline rather than by boat, and an attempt to devise a way of removing a sand bar at the mouth of the Baram River in Sarawak so as to make the river navigable for at least 60 miles.

All these projects are done on direct contract, and represent about half the work of the station. The other half is divided equally between research work with no specific client in mind and more basic studies of hydraulic science. Theoretical work at the station has shown, for example, that it is possible to obtain perfect dynamic similarity when modelling the process of sediment transport, and two channels of the same shape but different sizes have been built to demonstrate this. This work provides a theoretical basis for the large models. The station costs about $£ 500,000$ per year to run and last year earned $£ 308,000$. Recently, as part of a review by the Ministry of Technology of research establishments, the station was asked to justify its existence to British industry by calculating how much money was saved as a result of work at Wallingford. By conducting a survey of the small number of projects where accurate costings are possible, 